\title{
ACADEMIC ACCULTURATION OF CHINESE DOCTORAL STUDENTS IN FINLAND
}

\author{
Li Wang ${ }^{1}$ and Pekka Räihä ${ }^{2}$ \\ ${ }^{1}$ Hubei University of Arts and Science and ${ }^{2}$ University of Tampere
}

\begin{abstract}
The number of Chinese students enrolling in Finnish higher education institutions has increased dramatically, but few studies have attempted to understand the academic acculturation of Chinese students in Finland, particularly at the doctoral level. Consequently, the aim of this study is to explore how Chinese doctoral students integrate into Finnish learning environment. Data in this study were collected using the case study approach. The findings revealed that although the participants encountered many challenges, they acknowledged that these challenges were temporary and natural. As a result of intercultural learning, they formed a new sense of self and acquired an intercultural learner identity. It is worth noting that although the acculturation process is a two-way change, it might take time for changes in the host university to mature and become apparent.
\end{abstract}

Keywords: Chinese doctoral students, Finnish higher education, intercultural learner, academic integration

DOI: https//doi.org/10.3176/tr.2021.3.02

Received 30 April 2021, accepted 20 May 2021, printed and available online 10 September 2021

\section{Introduction}

Higher education institutions in Finland have been progressively focusing on global cooperation and educational internationalization (Aho et al. 2006). In the academic year 2017-2018, there were 20,362 international degree students enrolled 
at Finnish universities and universities of applied sciences (CIMO 2018). These students were from European Union (24\%), non-European Union (14\%), Asia (45\%), Africa (10\%), North America (3\%), and Latin America and the Caribbean (3\%). Around $20 \%$ of international students were admitted in doctoral degree programs (CIMO 2018).

Several reasons make Finland an attractive destination for international students. Firstly, Finnish higher education has always enjoyed a high reputation for its quality, efficiency, and internationalization. Secondly, higher education in Finland is less commercialized than in many Anglophone countries. Thirdly, although new nonEU/EEA students need to pay for their studies in Finland after August 2017, tuition fees are significantly less than those paid in other countries. Fourthly, the proportion of English-taught programs in Finnish higher education system is relatively high. Lastly, the Finnish government allows international students to stay in Finland looking for work for up to one year after they graduate (Li and Pitkänen 2018).

As for Chinese doctoral students, they come to Finnish universities to acquire knowledge and advanced information. However, due to the different learning culture between Finland and China, they might be shocked by the unpredicted challenges and their inability to deal with academic difficulties effectively (Bai 2016; Mesidor and Sly 2016). Although the increasing amount of research referred to learning experiences of Chinese doctoral international students has been done based in universities in the United States, the United Kingdom, and Australia, our knowledge of Chinese doctoral students in Finnish universities is scarce (Aittola 2017; Pappa et al. 2020). Therefore, given the significant proportion of Chinese students at Finnish campuses, and the limited research on Chinese doctoral students in Finland, this study aims to investigate learning experiences of Chinese doctoral students at Finnish universities. The four research questions will be addressed: (1) how do the participants perceive their intercultural learning difficulties in Finland? (2) what strategies do the participants adopt to overcome challenges in their academic acculturation? (3) what do the participants obtain from their academic acculturation? (4) is the preference for contacting the academic culture of the host country the primary factor resulting in an acculturation's orientation? The findings of this study may help Chinese doctoral students obtain a good understanding of many difficulties they experience in Finland, thus enabling a smooth academic transition to the new environment.

\section{Chinese international students in Western higher education}

Since the encounter of Confucius and Socrates, the discussions on the drastic differences of features between Chinese learners and Western learners have seemingly never ceased (Hodkinson and Poropat 2014). According to the previous research, views on the learning features of Chinese learners are contradictory ( $\mathrm{Li}$ and Pitkänen 2018). Some scholars view Chinese learners as quiet, passive, obedient, or lacking critical thinking, while others consider them to be open-minded, active, and 
independent. For example, there is a commonly held belief that Chinese learners rely heavily on rote learning. Rote learning is often thought to relate to surface learning approach rather than deep learning approach (McMahon 2011). Samuelowicz (1987) revealed that Chinese students' learning process is seen as reproductive as opposed to analytical or skeptical. In his survey, over $30 \%$ of Australian lectures felt that Asian students were more comfortable with memorization and unwilling to think deeply. Some studies have found that Chinese learners are usually obedient and reluctant to publicly challenge their teachers. The behaviors of challenging teachers and expressing independent judgment in the Confucian tradition are perceived as disrespectful and brash (Yan 2008; Wang 2019; Zhao 2007). In addition, Chinese learners are more likely than Western learners to expect the instructor to provide fixed answers directly rather than exploring knowledge led by the instructor. Zhao (2007) found that most Chinese learners are passive in answering questions and engaging in group discussions. When asked to express their own opinions in class, they tend to hide behind others. For many Chinese students and teachers, the twoway communication is normally perceived as an ineffective teaching approach because it wastes time.

However, new studies have brought new understanding of Chinese learners' characteristics (Tavakol and Dennick 2010; Wang 2010). Rao and Chan (2009) suggested that the Chinese learning style is more complex and dynamic than it appears and that the previous research is over simplistic and culturally biased. Gan (2009) indicated that the unique learning features of Chinese learners should be reexamined and more empirical research is needed. Cheng et al. (2011) investigated the relationship between learning approaches and academic outcomes from 129 local American students, 121 Chinese students in the United States, and 134 Chinese students in China, and found that although both Chinese students in China and Chinese students in the United States were less active than local American students in class, the learning achievement of the three samples did not appear obviously differ.

Due to specific cultural antecedents and social structures, the investigation of the characteristics of Chinese learners is complicated (Gao and Watkins 2002). It seems inappropriate to take Western-centric concepts as universally valid and impose those concepts on non-Western subjects (Shi 2006). Doing so might run the risk of judging Chinese students with the standards of Western education and putting Chinese students and Western students on opposite sides of a dichotomy. Therefore, more empirical research should be done on the details of learning experiences of Chinese students in Western higher education.

\section{The context: doctoral education in Finland}

The system of Finnish doctoral education is established on a strong welfare society and equal opportunities for all citizens (Cornér et al. 2018). For the past three decades, doctoral education reform has been one of the important development 
areas in Finnish education policies. Following the recommendations of the European University Association and its Council for Doctoral Education, the development of Finnish doctoral education has undergone three stages: (1) traditional doctoral education (before 1994); (2) the doctoral program model (1994-2011); (3) the doctoral school model (2011- present). The modern doctoral education in Finland launched in 1994. Since then, the responsibility of policy formulation of doctoral education has changed partly from the national level to the international level (Kivistö et al. 2017).

In line with the Bologna Process and European Qualifications Framework (EQF), the main goals of the latest Finnish doctoral education reform are to restructure national doctoral education to meet the needs of international economic competition, to enhance universities' responsibilities in doctoral education, and to increase educational flexibility through more effective cooperation between institutions (Aittola 2017). In order to achieve these goals, the national higher education system in Finland has provided a high level of trust and autonomy for doctoral training in Finnish universities. At the national level, the Finnish Ministry of Education and Culture does not have strict regulations on doctoral education. It just provides a loose framework for the structure of doctoral training. Finnish universities are responsible for the admission procedures, learning outcomes, supervision practices, and the assessment of doctoral programs and dissertations (Kivistö et al. 2017). This high degree of autonomy in doctoral policies has greatly contributed to the increase in Finnish international doctoral recruitment (Pappa et al. 2020). Correspondingly, the presence of international doctoral students has had a significant impact on many research fields in Finland, especially in the fields of science such as medicine, technology, mathematics, and engineering (Pyhältö et al. 2012).

\section{Theoretical framework}

Berry (2005) develops a classic strategies model for acculturation. According to him, acculturation is "the dual process of cultural and psychological change that takes place as a result of contact between two or more cultural groups and their individual members" (Berry 2005: 698). Different to previous unidimensional acculturation models which posit that if a person becomes more attached to the host culture, his/her retention of the heritage culture will be correspondingly weakened (Cheung-Blunden and Juang 2008), Berry believes that the process of acculturation does not automatically imply that individuals will abandon their original culture (Schwartz et al. 2010). In Berry's concept, not all individuals acculturate in the same orientations (Russell et al. 2010). They could choose different ways of adapting to the host culture.

According to Berry (2005: 704), the acculturation model has two basic dimensions: (1) a relative preference for maintaining one's heritage culture and identity; (2) a relative preference for having contact with and participating in the larger society along with other ethnocultural groups". These two dimensions 
create four types of orientations or strategies for individuals, which are integration, assimilation, separation, and marginalization. Specifically, integration occurs when individuals strive to maintain their original culture while at the same time valuing the host culture. Assimilation refers to the refusal to retain the original culture and the complete acceptance of the host culture. Separation describes individuals who avoid the cultural contact with the host country while maintaining their original culture. Marginalization is present when individuals reject their original culture and avoid involvement with host culture at the same time. Berry (1997) found that the most preferred strategy used by sojourners is integration which can produce fruitful outcomes. Berry also indicated that sojourners experience less socio-cultural stress when they employ integration; whereas the socio-cultural stress of marginalization is high. The assimilation strategy produces a modest level of socio-cultural stress.

\section{Research methodology}

This study takes the form of a qualitative approach, because rather than attempting to find statistically significant relationships, this research intends to examine the learning experiences of Chinese doctoral students in Finland. The use of a qualitative approach in this study provides researchers with accurate and deep descriptions about what is happening among participants within a specified setting, and helps readers understand the reality in a natural and holistic way (Yin 2009).

The qualitative research follows a case study design. It is widely believed that the case study approach is preferable when a researcher has little control over a complex social phenomenon but desires to understand it (Flyvbjerg 2011). This study attempts to understand the learning experiences of Chinese postgraduate students in Finnish learning culture in details, thus, the strength of case study approach allows the researchers to obtain in-depth relevant data within a specific context.

Data was collected by the first author through semi-structured interview. In order to ensure that the interview protocol can yield important information related to the research aim, this study conducted a pilot interview prior to data collection. According to the principle that the sample size of a reasonable pilot study is $10 \%$ to $20 \%$ of the actual study (Yin 2009), two Chinese doctoral students were selected to participate in the pilot interview. One student was in the field of education and another came from the field of chemistry. The pilot study not only allowed the author to refine the participants' criteria and interview questions, but also enabled the author to identify the pitfalls in interviewing techniques, including the use of recordings, avoiding noise interference, and time control. Most importantly, the pilot interview made the author aware of the importance of the skills of asking sensitive questions.

After the pilot interview, nine Chinese doctoral students who were on doctoral programs at three large research-intensive Finnish universities were interviewed individually for between 60 and 90 minutes. The criteria for selecting participants included: (a) they should have been born, raised, and completed both a bachelor and a master's degree in China, (b) they should be currently doctoral students in 
Finland, and (c) they should have completed at least one year of study programs during the period of interview. The first criterion was mentioned because it could ensure the purity of the sample. If some participants have studied overseas before coming to Finland, they might not feel in similar way as those who went abroad for the first time. The homogenous sampling strategy allows researchers to have an in-depth understanding of an experience shared by the participants with similar characteristics while comparing. The second criterion was mentioned because it was related to the subjects of this study. The reason to choose Chinese doctoral students as the research subjects was that they accounted for a large proportion of Chinese overseas students in Finland. Therefore, it was easy to recruit them to participate in this study. Moreover, their perceptions of academic learning may be more representative, since they had been educated in Chinese higher education as bachelor students and master students before they came to Finland. Meanwhile, Finnish educators may have higher academic expectations of doctoral students than undergraduate students and master students, such as hoping them to become independent researchers with critical thinking. The third criterion emphasized the length of study time in Finland. The participants should have ample opportunities to experience the different learning culture in Finnish higher education. Demographic profiles of interviewed Chinese postgraduate students are showed in Table 1. The language used in all interviews was Mandarin which was the official language of China. With the participants' permission, all the conversations were recorded.

After the data was collected, the interview recordings were listened repeatedly in order to improve researchers' understanding and interpretations. The interview data were transcribed verbatim in the original interview language. And then the transcription was translated into English. Yin (2009) suggests that in order to improve the readability of the text, it is not necessary to maintain the translation of interview excerpts as the exact linguistic form in sociolinguistic studies. Therefore, unnecessary

Table 1. Demographic profiles of interviewed Chinese doctoral students

\begin{tabular}{llllll}
\hline Participants & Gender & Major & $\begin{array}{l}\text { Degree } \\
\text { program }\end{array}$ & $\begin{array}{l}\text { The length of } \\
\text { doctoral study }\end{array}$ & $\begin{array}{l}\text { Marital } \\
\text { status }\end{array}$ \\
\hline P1F & Female & Education & Ph.D. & Four years & Married \\
P2M & Male & Business & Ph.D. & Two years & Married \\
P3M & Male & Mathematics & Ph.D. & One year & Single \\
P4F & Female & Forestry & Ph.D. & Two years & Single \\
P5M & Male & Psychology & Ph.D. & Three years & Single \\
P6M & Male & Education & Ph.D. & One year & Single \\
P7F & Female & Computer & Ph.D. & Two years & Single \\
P8F & Female & Education & Ph.D. & Three years & Married \\
P9F & Female & Chemistry & Ph.D. & Three years & Married \\
\hline
\end{tabular}

(Note: $\mathrm{P}=$ Participant; $\mathrm{M}=$ Male; $\mathrm{F}=$ Female) 
repetitions and redundancy in this research were omitted without mispresenting the meaning of interviews. Each English translation was sent back to the participants to check for the accuracy. Meanwhile, all relevant paper materials, such as consent forms, on-the-spot notes, and transcripts, were stored in locked drawers and will be deleted and destroyed as soon as the study is complete.

Thematic analysis was used in this study for identifying, organizing, and presenting qualitative data (Alhojailan 2012). It allows researchers to link an analysis of a theme to the whole content. Furthermore, it provides researchers with an opportunity to understand the potential of any issue in depth via interpretations (Braun and Clarke 2006). In order to generate insights of interpretations on how the participants perceive their learning experiences in the different learning culture, the procedure of the thematic data analysis in this study followed the six-phase strategy provided by Braun and Clarke (2006), including getting familiar with raw data, generating initial codes, searching for themes, reviewing themes, defining and naming themes, producing the report. In the next section, the results of this research will be discussed.

\section{Findings}

\subsection{Intercultural learning challenges}

Regarding their academic experiences in Finland, all of the participants in this study indicated that they encountered significant pedagogical challenges from what they were used to in China. These challenges included (1) language insufficiency; (2) knowledge gap; (3) interactions with supervisors; and (4) expectations from Chinese family.

\subsubsection{Language insufficiency}

Language insufficiency has been identified as one of the main inhibitors that prevented Chinese students from achieving their academic goals in a Western setting. In the interview, many participants indicated that their ability of academic English had been challenged. The data showed that participants who studied humanities and social sciences encountered more language challenges than those who studied natural sciences. For example, participant six felt nervous to speak up publically:

At the beginning of my study in Finland, I seldom put forward my ideas in class or communicated with other students because I was afraid that my English pronunciation might be mocked. Once, I finally got the courage to participate in a discussion, but when I finished my words, the other students gave me a very confused look. At that moment, I felt very shameful. (P6M)

There are at least two reasons that contribute to the problems of Chinese students' oral communication. First, an oral English class in China usually has 40-60 students (Wang 2019). It is difficult for every student can get a chance to practice their oral skills. Second, influenced by the result-oriented teaching, the grammar-translation 
approach plays a dominant role in the English class in China. Teachers overly focus on the basic knowledge of the language and keep explaining the construction of sentences from the beginning to the end of class. Students learn grammar, vocabulary, and sentence construction passively (Greer 2005).

When talking about academic writing in the forms of course papers, journal manuscripts, and conference proposals, most participants indicated that in China, they mainly wrote for tests. In order to get high scores, they often had some specific models to follow. Critical and independent thinking was not encouraged in Chinese academic writing. Therefore, when they were exposed to graduate-level writing in Finland, they felt that their ability to write critically was a challenge. Just as participant one commented:

Chinese students like to follow certain 'successful models' or formula to write. The norms of English academic writing in Finland are quite different. You can write whatever you want. This freestyle made me feel confused in the beginning. I did not know what to write and how to write. Sometimes, I feel that having a lot of freedom may not be a good thing because you have to rely on yourself to find a right way to write. (PIF)

The feedback from participant one indicated that the transformation from imitating the "successful models" to having freedom in English writing was not easy for her. When she faced the new and free writing norms of Finland, she felt emotional pressure. Her comments suggested that she was not well-prepared for the new academic writing requirements.

\subsubsection{Knowledge gap}

In this study, some of the participants mentioned that their difficulties in academic acculturation were caused by the different curriculum content and structure between Finnish and Chinese universities. For instance, participant two expressed that sometimes, the Finnish teachers assumed that Chinese students had the same knowledge background as Finnish students. This assumption made Chinese students encounter challenges.

When I studied the course of qualitative research methods, I felt very frustrated. I never took any courses on research methods before I came to Finland. However, in the first semester of my doctoral program, my course teacher thought I knew as much about the subject as the Finnish students, so his lecture was too advanced. I didn't understand what he was talking about in class, and I didn't know how to finish my homework. I felt like I was being driven crazy. In the end, I had to quit this course. (P2M)

Participant three indicated that although some courses offered by his program in Finland had the same name as the ones he had studied at his former Chinese university, the content of the course was different. Therefore, he had to study those courses again. He added: 
Before I studied in Finland, I thought I just needed to follow the original research direction and continue to do what I used to do. Unfortunately, the situation was not the same as I expected. There was a lot of knowledge that I had never studied in my former university in China, so I had to start from the beginning. Ifelt frustrated at that time. (P3M)

The feedback from participant three showed that he was fully aware of the different curriculum content and structure existing between the Finnish educational system and the Chinese educational system. The disequilibrium state in curriculum blocked him from actively participating and achieving. In order to catch up with the other Western students, he had to study hard to overcome this obstacle.

\subsubsection{Interactions with supervisors}

To a large extent, the academic success of international students depends on the effective interaction with their native supervisors (Yan 2008). The data in this study showed that participants encountered some challenges when they interacted with their supervisors. For example, participant seven shared her experience:

I expect my supervisor to tell me what to do and how to do it. And I also hope my supervisor can give me a heads up before I encounter problems. However, my Finnish supervisor's thought is different from mine. When I asked him "how to do this research?" or "what approach should I use?" he always said, "It depends on you." When I heard his responses, I felt confused. In my eyes, he was an irresponsible supervisor. If I knew how to do it, why should I need studying? (P7F)

In Chinese students' minds, a responsible supervisor should unconditionally impart all his or her knowledge and skills to the students. Under the influence of this culture, participant seven expected her supervisor to give her clear instructions and show the path step by step. She felt insecure without the supervisor being around her. However, her supervisor expected her to explore the knowledge and skills on her own through trial and error. As a result, the different expectations of how to acquire knowledge and skills caused confusion for her.

Some participants in this study mentioned that they expected their supervisors to give them explicit and rigid supervision. However, the management model of Finnish supervisors focused on individual freedom and self-motivated learning. This new regulation mode exposed the participants to the challenge of self-management and self-discipline. Participant two commented:

I do not like this freedom [of the doctoral supervision]. I expect my supervisor to be around me and supervise me strictly. Unfortunately, I have to study alone. Sometimes, I feel depressed because I do not know how to continue my study. I know most Western students like freedom. They do not like being over-regulated by their supervisors. But as Chinese students, we hope supervisors can maintain high interference in our learning process. (P2M) 
In Chinese learning culture, rules and regulations are the prerequisite to ensure the process of imparting quality education to students. A good student should be strictly cultivated. Influenced by the strict supervision mode in China, participant two lacked the understanding of self-management and self-discipline. When he brought his inherited value onto the Finnish campus, he encountered problems in arranging his study.

\subsubsection{Expectations from Chinese family}

The ages of participants in this interview were between 25-36 years old. The reports from them showed that they were anxious and worried about their dating, marriage, or family life. Just as participant four said:

In Chinese culture, men can get married at any time, while women can't. If a woman is not married before the age of 27, she is a 'leftover'woman who is worth less and less. I am already 30 years old. My parents wanted me to give up my current doctoral study and return back to China to find a guy to get married. But it is hard to make this decision. Every night, I cannot fall asleep when I think of my future. (P4F)

The term 'leftover woman' has been used by official Chinese media since 2007 (BBC News 2013). This term refers to single women over the age of 27. In Chinese society, if a woman does not marry at a certain age, she will be discriminated against. The feedback from participant four indicated that her academic development had been negatively affected by this social bias. Participant two said that he was under great pressure to take care of his family while pursuing his doctoral degree. He shared his story:

I'm a married man and I think I have more challenges than the average international Chinese student. As a doctoral student, I am not able to make enough money to support my family. Meanwhile, as the only son in the family, I should take care of my parents. However, I am far away from my parents and make them constantly worry about me. My doctoral process is more stressful. I feel like I can't breathe. (P2M)

A family is one of the social support resources that influence students' acculturation (Misra et al. 2003). For most international students who are married, a family might be a source of stress in their learning process. Compared to the unmarried overseas students, participant two was under more mental and material pressure. He needed to be responsible for his child, wife, and parents. These responsibilities and pressures posed challenges to the successful completion of his studies.

\subsection{Academic acculturation strategies}

In this study, although most participants encountered many challenges, they acknowledged that these challenges were temporary and natural. In order to survive in the new academic environment, they tried to cope with their stress and challenges through various strategies. Participant eight stated: 
Studying abroad is a journey with lots of pressure. Although I was exhausted during this journey, investing efforts and time in my study was the only strategy that I could use. I believe that efforts can change my fate. (P8F)

For some participants, seeking help was considered a necessary strategy to overcome academic difficulties. They expressed that the benefits and supports they received from co-nationals and family served as mediators for them to adjust to the new cultural environment. Participant six stated:

When I encounter difficulties in my study, I usually turn to my Chinese friends for help, especially the senior Chinese students. The reason I mainly ask Chinese friends for help is language and culture. We speak the same language, and there is a mutual understanding without a need for much explanation. After communicating with them, I feel more relieved and relaxed. (P6M)

For participant six, the advice and help from senior Chinese students were useful. Because of the language barrier and cultural distance, he felt that it was easier to communicate with co-nationals and get the sympathy. The accounts of participant six were consistent with the previous research results that senior students were the preferred source of information to help Chinese students (Yan 2008).

\subsection{Academic development and personal growth of the participants}

\subsubsection{Learning ability development}

As the learning experiences deepened, most participants in this study indicated that some of their academic difficulties decreased. In particular, the participants' English proficiency has improved noticeably after one year study in Finland. Just as participant five expressed:

When I first started my studying in Finland, my mood was just like the Finnish winter - dark and cold. I was not able to follow the teachers in class at all. After one year, I no longer feel nervous to communicate with my teachers and classmates. Although I still have problems in academic writing, I am confident to improve it. (P5M)

English adequacy was perceived as one of the biggest beneficial gains of studying abroad (Yan 2008). For the participants, although English language is a major source of stress in their early stages of intercultural learning, they consciously negotiate their ways to improve their English level. The achievement of participant eleven confirmed the study of Gill (2007), which shows that obstacles can promote personal growth.

\subsubsection{Tolerance with academic differences}

The intercultural learning experiences also enabled the participants to get familiar with the Finnish higher education system and integrate into different learning 
practices. The data revealed that there were noticeable changes in the students' attitudes towards cooperative learning. Participant one said:

Most of my peers, including me, did not have the enthusiasm to participate in cooperative learning at the beginning of our study in Finland, because this learning approach was not valued in China. But as time went on, I had gradually realized that cooperative learning was beneficial. I liked to share my thoughts with other group members. I felt that I became more initiative in learning than I was in China. (PIF)

The different academic requirements between Finnish education and Chinese education pushed the participants to make changes in their learning habits. For participant one, she was able to analyze the benefits and drawbacks of different learning contexts. She adopted a positive attitude to fit into the existing educational framework. Her experiences showed that encountering the differences of learning cultures can provide the participants with more opportunities to make changes and develop themselves in different learning practices (Gill 2007).

\subsubsection{Self-identity development}

Apart from the changes in understanding of the new learning practices, most participants indicated that the reconstruction of self-identity was an important outcome of their intercultural learning. Just as participant nine reported:

I have got two systems of value in my brain: one is for Finland and one is for China. Sometimes, I feel that I am half Chinese and half Finnish. (P9F)

The comments of participant nine indicated that she had rebuilt her new identity through the process of intercultural negotiation. This new identity allowed her to integrate new learning culture while retaining the learning culture she inherited. As Zhu (2012) has pointed out, the process of combining an individual's original academic culture with the target academic culture to develop international academic culture is a process of opening one's potential universe. The reconstruction of identity leads to the participants' personal growth (Gill 2007).

\section{Discussion}

The recruitment of international students itself cannot simply bring intercultural education to the universities of the host country (Wang 2010). The purpose of this study is to make contributions to the literature on the academic acculturation of Chinese doctoral students in Finnish higher education. It has explored Chinese doctoral students' challenges they encountered, the acculturation strategies they adopted, and the changes they went through.

The data revealed that the switch from the Chinese learning environment to the Finnish learning environment was not smooth and immediate. The differences 
between Chinese learning culture and Finnish learning culture posed great challenges to the participants in their initial academic learning. Although they had an open mind to the new learning environment, they still needed time to accept the values behind Finnish teaching standards and norms. In order to achieve their academic goals, the participants had to constantly negotiate their original learning culture with Finnish academic expectations. It is worth noting that fitting into the Finnish learning environment does not mean that the participants had to throw away their inherited learning habits and completely embrace the Finnish learning style. Instead, the participants gradually developed a new learner identity through the negotiation between Chinese learning culture and Finnish learning culture. This new learner identity is eclectic and compromised.

The findings of this study also indicated that although the acculturation process is a two-way change, the influence of the host group on foreign students and that of foreign students on the host group may be different in speed and extent. Some participants in this study indicated that the impact of their culture and educational backgrounds on the target academic culture was limited. They felt that their influence was mainly to bring the diversity to the host group. It is possible, however, that it might take time for changes in the target group to mature and become apparent.

The findings of this study supplement the existing body of knowledge relating to Berry's acculturation theory. In Berry's research, acculturation is mainly conceptualized as a desire or preference for either maintaining one's inherited culture, or contacting with the host culture, which leads to four distinct possible outcomes (Berry 2005). However, this study found out that the preference for contacting the host academic culture might not be the primary factor resulting in an acculturation's orientation. Taking academic integration as an example in this study, the lack of language ability or intercultural competence, the pressure of the economic situation, and the academic supervisors' attitudes might lead to the failure of academic integration. Thus, although international students may not be able to integrate into the host academic culture, the assumption that this is merely because they prefer not to make the contact with the host academic culture not only misrepresents their intentions but also fails to capture the richness of their intercultural learning experiences.

Since an increasing number of students from China will continue to study in Finnish higher education at a doctoral level, their learning experiences deserve additional and sustained attention. Based on the discussions above, this study suggests that the Finnish universities have a responsibility to guide Chinese doctoral students in becoming aware of the different learning norms in their host institutions and to encourage them to explore a new way of learning. This means that rather than simply introducing academic norms without a clear explanation, Finnish universities should help Chinese postgraduate students understand the values behind Finnish teaching standards and norms. And they should trust that Chinese students have potential abilities to integrate well into Finnish learning culture. 


\section{Acknowledgements}

The completion of this article has been supported by the project of Hubei University of Arts and Science (XK2020021).

Addresses:

Li Wang (corresponding author)

School of Chinese Literature and Media

Hubei University of Arts and Science

441053 Xiangyang

China

E-mail: xiaqiuwang@hotmail.com

Phone: (+86-0710)3591876

Pekka Räihä

Faculty of Education and Culture

University of Tampere

33851Tampere

Finland

E-mail: pekka.raiha@tuni.fi

Phone: +358401904172

\section{References}

Aittola, H. (2017) "Doctoral education reform in Finland: institutionalized and individualized doctoral studies within European framework". European Journal of Higher Education 7, 3, 309-321.

Alhojailan, M. I. (2012) "Thematic analysis: a critical review of its process and evaluation". West East Journal of Social Sciences 1, 1, 39-47.

Bai, J. (2016) "Perceived support as a predictor of acculturative stress among international students in the United States". Journal of International Students 6, 1, 93-106.

BBC News (2013) Available online at <http://english.cri.cn/7046/2013/03/05/167s751821_1.htm>. Accessed on 18 April 2019.

Berry, J. W. (2005) "Acculturation: living successfully in two cultures". International Journal of Intercultural Relations 29, 6, 697-712.

Berry, J. W. (1997) "Immigration, acculturation, and adaptation". Applied Psychology 46, 1, 5-34.

Braun, V. and V. Clarke (2006) "Using thematic analysis in psychology". Qualitative Research in Psychology 3, 2, 77-101.

Cheng, H. Y., H. L. Andrade, and Z. Yan (2011) "A cross-cultural study of learning behaviours in the classroom: from a thinking style perspective". Educational Psychology 31, 7, 825-841.

Cheung-Blunden, V. L. and L. P. Juang (2008) "Expanding acculturation theory: are acculturation models and the adaptiveness of acculturation strategies generalizable in a colonial context?". International Journal of Behavioral Development 32, 1, 21-33.

CIMO (Centre for International Mobility). Statistics on international mobility periods of higher 
education students in Finland 2017. Available online at $<$ https://www.oph.fi/sites/default/files/ documents/167121_factsexpress9b_2018_0.pdf $>$. Accessed on 12 May 2019

Cornér, S., K. Pyhältö, J. Peltonen, and S. E. Bengtsen (2018) "Similar or different? Researcher community and supervisory support experiences among Danish and Finnish social sciences and humanities PhD students". Studies in Graduate and Postdoctoral Education 19, 2, 274-295.

Flyvbjerg, B. (2011) “Case study”. In N. K. Denzin and Y. S. Lincoln, eds. The Sage handbook of qualitative research, 301-316. 4th ed. Thousand Oaks, CA: Sage.

Gan, Z. (2009) “'Asian learners' re-examined: an empirical study of language learning attitudes, strategies and motivation among mainland Chinese and Hong Kong students". Journal of Multilingual and Multicultural Development 30, 1, 41-58.

Gill, S. (2007) 'Overseas students' intercultural adaptation as intercultural learning: a transformative framework". Compare 37, 2, 167-183.

Gong, Y. and S. Chang (2007) "The relationships of cross-cultural adjustment with dispositional learning orientation and goal setting: a longitudinal analysis”. Journal of Cross-Cultural Psychology 38, 1, 19-25.

Hodkinson, C. S. and A. E. Poropat (2014) "Chinese students' participation: the effect of cultural factors". Education + Training 56, 5, 430-446.

Kivistö, J., E. Pekkola, and T. Siekkinen (2017) "Latest reforms in Finnish doctoral education in light of recent European developments". European Journal of Higher Education 7, 3, 291-308.

Li, H. and P. Pitkänen (2018) "Understanding the integration of mainland Chinese students: the case of Finland”. Nordic Journal of Migration Research 8, 2, 107-115.

Marshall, C. and G. B. Rossman (2006) Designing qualitative research. 4th ed. Thousand Oaks, CA: Sage

McMahon, P. (2011) "Chinese voices: Chinese learners and their experiences of living and studying in the United Kingdom". Journal of Higher Education Policy and Management 33, 4, 401-414.

Mesidor, J. K. and K. F. Sly (2016) "Factors that contribute to the adjustment of international students". Journal of International Students 6, 1, 262-282.

Misra, R., M. Crist, and C. J. Burant (2003) "Relationships among life stress, social support, academic stressors, and reactions to stressors of international students in the United States". International Journal of Stress Management 10, 2, 137-157.

Pappa, S., M. Elomaa, and S. Perälä-Littunen (2020) "Sources of stress and scholarly identity: the case of international doctoral students of education in Finland". Higher Education 1, 2, 1-20.

Pyhältö, K., A. Toom, J. Stubb, and K. Lonka (2012) "Challenges of becoming a scholar: a study of doctoral students' problems and well-being”. International Scholarly Research Network Education 12, 1-12.

Rao, N. and C. K. K. Chan (2009) "Moving beyond paradoxes: understanding Chinese learners and their teachers". In C. K. K. Chan and N. Rao, eds. Revisiting the Chinese learner. changing contexts, changing education, 3-32. Hong Kong: The University of Hong Kong, China, Comparative Education Research Centre.

Russell, J., D. Rosenthal, and G. Thomson (2010) "The international student experience: three styles of adaptation". Higher Education: The International Journal of Higher Education and Educational Planning 60, 2, 235-249.

Samuelowicz, K. (1987) "Learning problems of overseas students: two sides of a story". Higher Education Research and Development 6, 2, 121-133. 
Schwartz, S. J., J. B. Unger, B. L. Zamboanga, and J. Szapocznik (2010) "Rethinking the concept of acculturation: implications for theory and research". American Psychologist 65, 4, 237-251.

Tavakol, M. and R. Dennick (2010) “Are Asian international medical students just rote learners?". Advances in health sciences education 15, 3, 369-377.

Wang, L. (2019) The learning experiences of Chinese postgraduate students at the University of Eastern Finland. Doctoral dissertation, University of Eastern Finland. Available online at $<$ https://erepo.uef.fi/handle/123456789/22099>. Accessed on 18 May 2019.

Wang, L. H. (2010) Chinese postgraduate Students in a British university: their learning experiences and learning beliefs. Doctoral dissertation, Durham University. Available online at $<\mathrm{http}: / /$ etheses.dur.ac.uk/196/>. Accessed on 18 June 2019.

Wang, L. and M. Byram (2018) “International doctoral students' experience of supervision: a case study in a Chinese university”. Cambridge Journal of Education 49, 3, 255-274.

Yan, K. (2008) Chinese international students' stressors and coping strategies in the United States. Doctoral dissertation, Arizona State University. Available online at $<\mathrm{https}$ ://www.springer.com/ gp/book/9789811033452>. Accessed on 20 June 2019.

Yin, R. K. (2009) Case study research: design and methods. 4th ed. Thousand Oaks, CA: Sage.

Zhao, Y. (2007) "Cultural conflicts in an intercultural classroom discourse and interpretations from a cultural perspective". Intercultural Communication Studies 16, 1, 129-136.

Zhu, J. (2012) Academic adjustment of Chinese students at German universities. Doctoral Dissertation, Humboldt-Universität zu Berlin. Available online at <https://www.academia.edu/21272227/ Academic_adjustment_of_Chinese_students_at_German_universities $>$. Accessed on 25 March 2019. 